\title{
The screw tip stent retriever for biliary drainage in a severe living donor liver transplant anastomotic stricture
}

The screw tip stent retriever (STSR) is an endoscopic device that allows for removal of biliary and pancreatic duct stents while maintaining guidewire placement. A few case reports of patients with biliary strictures in whom standard dilation techniques have failed have described success of the STSR for dilating and traversing high grade benign and malignant strictures [1 - 3]. In this video case report ( Video 1), we show that it can also be used in living donor liver transplant (LDLT) recipients with high grade strictures and relatively small upstream intrahepatic bile ducts.

The patient was a 62-year-old woman who presented with elevated liver tests 3 years after left lobe LDLT. Subsequent magnetic resonance cholangiopancreatography showed a biliary anastomotic stricture and mild intrahepatic biliary dilatation (-Fig.1a). A cholangiogram obtained through endoscopic retrograde cholangiopancreatography (ERCP) revealed near complete obstruction at the level of the surgical anastomosis ( Fig. 1 b). A 0.018-inch guidewire was able to traverse the stricture; however, neither the CannulaTome (Cook Medical, Bloomington, Indiana, USA) nor a tapered tip cannula could pass. An 8.5-Fr STSR was then used to advance across the stricture by applying gentle pressure and clockwise torque ( $\vee$ Video 1 ), which then allowed for balloon dilation and placement of a $10 \mathrm{~mm} \times 6 \mathrm{~cm}$ fully covered metal stent. A $10 \mathrm{Fr} \times 20 \mathrm{~cm}$ plastic stent was deployed within the metal stent to reduce migration risk ( $>$ Fig. 2 a). No adverse events occurred.

Liver tests returned to normal and followup ERCP 3 months later showed stricture resolution ( $\mathbf{F i g .} \mathbf{2} \mathbf{b}$ ). The patient is now at 2.5 years of follow-up and continues to have normal liver tests.

In conclusion, the STSR can be an effective tool for traversing and dilating high grade anastomotic strictures in LDLT re-
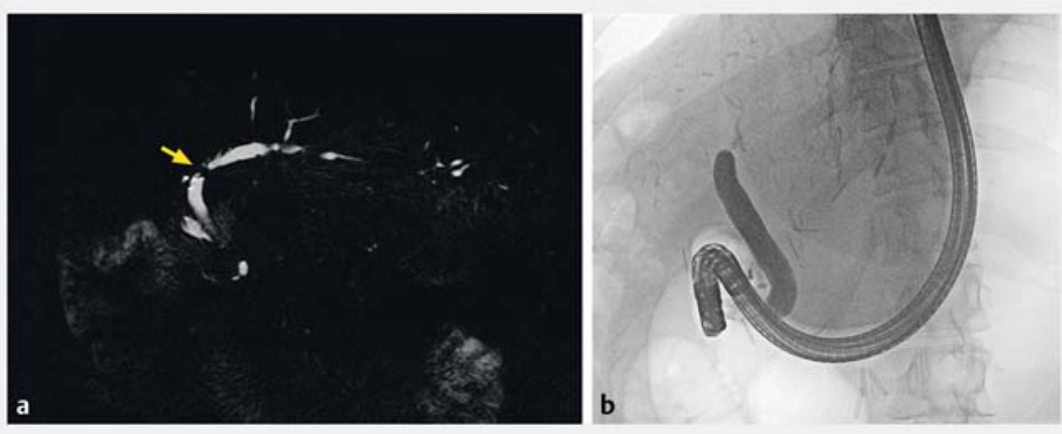

- Fig. 1 Imaging studies of anastomotic stricture. a Magnetic resonance cholangiopancreatography demonstrating high grade stricture (arrow). b Fluoroscopic appearance of the stricture on endoscopic retrograde cholangiopancreatography.

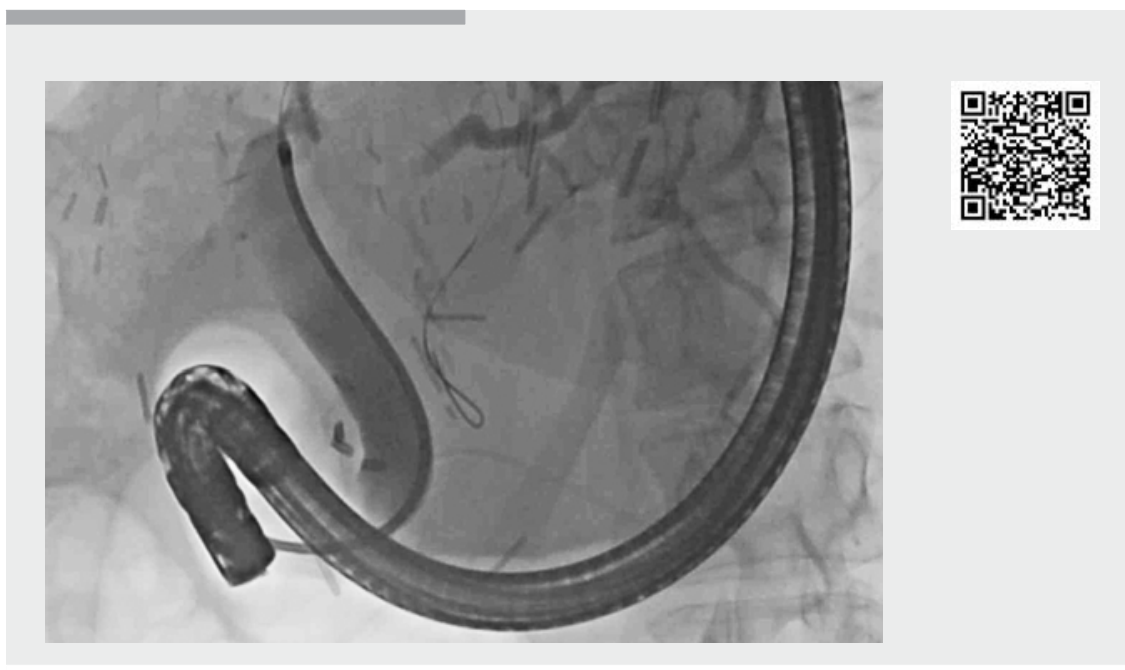

$\checkmark$ Video 1 Use of the screw tip stent retriever to traverse a high grade biliary anastomotic stricture in a living donor liver transplant recipient.

cipients, thereby avoiding percutaneous drainage or surgical revision.

Endoscopy_UCTN_Code_TTT_1AR_2AG

Competing interests

Dr. Arain is a consultant for Olympus, Boston Scientific, and Medtronic. Drs. Kouanda and Avila declare that they have no conflict of interest.
The authors

Abdul Kouanda, Patrick Avila, Mustafa Arain Department of Medicine, University of California, San Francisco, California, United States 

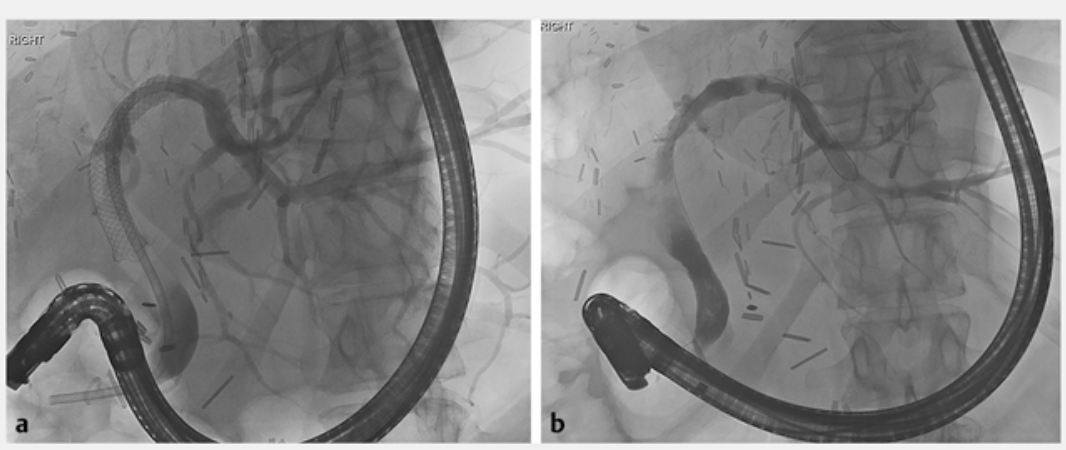

- Fig. 2 Endoscopic retrograde cholangiopancreatography (ERCP) images. a A $10 \mathrm{~mm} \times 6 \mathrm{~cm}$ fully covered metal stent was deployed across the anastomosis with the distal end within the native bile duct. A $10 \mathrm{Fr} \times 20 \mathrm{~cm}$ plastic stent was subsequently placed through the metal stent to reduce migration risk. $\mathbf{b}$ Follow-up ERCP 3 months later showed resolution of the biliary stricture after removal of the previously placed stents.

\section{References}

\section{Abdul Kouanda, MD}

Department of Gastroenterology and Hepatology, University of California, 513 Parnassus Avenue, San Francisco, CA 94143, United States

Fax: +1-415-476-0659

abdul.kouanda@ucsf.edu
Bibliography

Endoscopy 2020; 52: E454-E455

DOI 10.1055/a-1164-7972

ISSN 0013-726X

published online 12.5.2020

(C) 2020. Thieme. All rights reserved.

Georg Thieme Verlag KG, Rüdigerstraße 14 , 70469 Stuttgart, Germany

\section{ENDOSCOPY E-VIDEOS}

https://eref.thieme.de/e-videos

口迎 Endoscopy E-Videos is a free

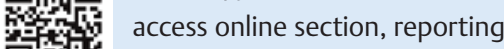
自解: on interesting cases and new techniques in gastroenterological endoscopy. All papers include a high quality video and all contributions are freely accessible online.

This section has its own submission website at https://mc.manuscriptcentral.com/e-videos 